\title{
A Review on Partial Replacement of Cement by Flyash and Effect of Steel Fibers
}

\author{
Mr. Anurag Verma ${ }^{1}$, Ms. Disha Srivastava ${ }^{2}$, Mr. Neelesh Kumar Singh ${ }^{3}$ \\ 1,2 (U G Student, Civil Engineering Department, SRMGPC, Lucknow, Uttar Pradesh, India) \\ ${ }^{3}$ (Assistant Professor, Civil Engineering Department, SRMGPC, Lucknow, Uttar Pradesh, India)
}

\begin{abstract}
Cement is a fine binding material which sets and strengthens when water is supplemented to it. It is largely used in construction with great advantages but cement with its wide range of properties has several disadvantages as well. Manufacturing of cement causes ill effect on environment at all stages of process. These include emissions of pollutantslike dust, gas, noise and vibration. Manufacturing of cement causes emission of the most common greenhouse gas i.e. carbon dioxide, from 5\% in cement structures to $8 \%$ in case of cement roads. Carbon dioxide is released by cement manufacturing both indirectly (emission of energy) and directly (heating of calcium carbonate). The cement factories produce upto 5\% of global artificial $\mathrm{CO}_{2}$ emission. This review paper presents the usage of fly ash by replacement of cement in our general construction. In addition, review of effect of steel fibers on concrete is also done.
\end{abstract}

Keywords: Cement, flyash, class C-flyash, class F-fly ash, HVFA, Green concrete, steel fibers.

\section{Introduction}

It is the main motive of concrete industry today to perform its level best without harming the environment balance. The excessive emission of greenhouse pollutants has caused the total imbalance in sustainable growth. It is the prime goal to achieve growth keeping in view the ecological impact. It greatly influences the environment and its various elements. As summarized below:

Impact on climate: These emissions of greenhouse gases directly impact the environment and the change in climate which occurs generally after 30 to 40 years is susceptible to change in a more frequent manner and thus influencing the life and property on a large scale.

Impact on ozone layer: The main greenhouse gas $\mathrm{CO}_{2}$ effect the ozone layer to a great extent and the famous ozone hole gets no reason to decrease.

Resource Productivity: The concrete industry uses all the materials such as cement on a very large scale and thus wastage of money and products and energy.

This is the very reason that usage of HVFA has gained wide range popularity. It is becoming the need of the nation because of its features like durability, resource efficiency, and sustainability, and cost effectiveness. HVFA can be defined as any concrete having 50\% content of flyash. This is known as green concrete and it is not harmful for the environment. In our project, what we are actually doing is replacing cement with flyash at different percentage and checking the strength at every point. This is called hit and trail method. The ratio of percentage at which strength comes out to be maximum will be our required ratio of percentage.

Flyash is the byproduct of combustion of coal. The reason behind choosing flyash as a replacement material can be further explained in the points below:

1.Flyash is also called "pulverized fuel ash" and is a coal combustion product thus easily available.

2. Green concrete is formed by mixing fly ash with concrete. It is so called as fly ash is environmental friendly.

3. Flyash if not used properly produces a lot of environmental problems as ground water contamination, fugitive dust, health issues etc.

4. Flyash has the required strength to replace cement in concrete and is highly durable.

5. Flyash is commonly replacing 0 to $30 \%$ of the cementitious material by mass.

6. Flyash is cost efficient and thus helps us in maintaining economical balance.

7. It is also said to reduce internal temperature and improve workability. Because of this, it results in ball bearing action of spherical particles of flyash.

8.It also improves the grading of the mixture because the fine particle distribution system is smoothened out.

9. It also reduces the amount of water required.

10. Flyash increases compressive strength, pumping ability, concrete finishing, flexural strength, corrosion, shrinkage and alkali silica reaction.

11. The most attractive property is durability of flyash concrete as compared to traditional PCC. 
The characteristics of HVFA strongly depends of flyash. HVFA comes with anextensive range of properties. Research haverevealed that HVFA is more crack resistant as compared to conventional PCC. This comes out as a result of decreased amount of water used, decrease in water-cement ratio and decrease in overall content of cement used. Talking about the disadvantages of HVFA, the development of strength in HVFA is slower than the concrete without flyash thus the setting time of HVFA is larger as compared to traditional concrete. This happens for both classes of flyash. The delay can be maximum for 2 hours. Class c flyash has higher calcium content therefore reduced setting time compared to class $\mathrm{F}$. The rate of increase in compressive strength depends on the level to which we are replacing the cement. Consistency and presence of different add mixtures also influence the strength variation.

Some researchers claim that it is important to add super plasticizer to gain the strength in the concrete as it provide required strength and susceptibility to the concrete.

\section{Literature Review}

1. P.Kumar Mehta ${ }^{[1]}$ has studied HVFA i.e. using concrete with a replacement of $50 \%$ cement through flyash by mass. He discussed the mechanisms of how incorporation of high volume of flyash improved workability, durability, minimized water demand and reduced sulphate attack and minimized cracking. He claimed that this technology will definitely help the developing countries like china and India.

2. Chao-Shun Chang, Chung-ho-huang, How-ji chen, Shu-ken Lin ${ }^{[2]}$ proposed a design mix method by using 20 to $80 \%$ flyash in place of cement. They used two types of class F flyash, one with $4.6 \%$ and other with $7.8 \%$ loss on ignition. They then performed tests for checking concrete properties. Tests clearly indicated that use of flyash increases setting time of concrete and thus development of strength takes time approximately 91 to 365 days. He formulated the relation between flexural and compressive strength of HVFA for all grades. The flyash withloss of ignition proposed superior mechanical properties. He finally came up with the result that $80 \%$ of class F-flyash can be used as a replacement in concrete by using a rational mixture proportion.

3. L.K.Crouch, Ryan Hewitt, Ben byard ${ }^{[3]}$ studied two HVFA mixtures, one class $\mathrm{C}$ and the other class $\mathrm{F}$ flyash and compared the results with TDOTA general used mixtures using flyash of same class in lower amount. He came up with the result that use of HVFA increases durability, minimizes void content and lowers the absorption as compared to TDOTA mixtures. The setting time increased by 2 hours at normal temperature i.e. 22 degree Celsius. They told that use of HVFA will be appropriate for warm weather conditions and it has comparable costs and increased compressive strength.

4. Yash Srivastava and Ketan Bajaj ${ }^{[4]}$ studied the performance of flyash in soil stabilization by replacing it with different soil for 10 to $60 \%$. His paper also deals with all the hardened properties as compressive strength and flexural strength of HVFAC through prisms and cubes with 35\%,50\% and 75\% replacement with flyash. Their result was that up to $50 \%$ replacement can be done with overall only $12 \%$ increase in cost.

5. Muhammad shahzada, Tufail, Khan, Bora Genturk and Jianqiang Wei ${ }^{[5]}$ studied the effect of high temperature on mechanical properties of limestone, concrete and quartzite. The samples were subjected to a temperature of 25 to 650 degrees for 2 hours. Compressive strength, tensile strength and modulus of elasticity were tested. They concluded that variation in temperature largely affects the concrete mechanical properties. As the temperature was increased, the compressive strength, tensile strength and modulus of elasticity decreased and the ultimate train increased.

6. H.W. Hwang and P.S. Song ${ }^{[6]}$ studied that the low strain capacities and tensile strengthof high strength concrete can be removed by using steel fibers. They added steel fibers at the volume fractions of $0.15 \%, 1 \%, 1.5 \%, 2 \%$. The toughness index improved with increase in fraction and reached a max at $0.15 \%$.

7. Bing Chen, Juanyu Liu ${ }^{[7]}$ made EPS concrete with a method similar to that of sand wrapping because expanded polystyrene is light weight and good energy absorbing material but it can even segregate at the time of casting. The results showed that EPS beads can be used in place of coarse and fine aggregate giving a density of $800-1800 \mathrm{~kg} / \mathrm{m}^{3}$ and a compressive strength of $10-20 \mathrm{MPa}$.

8. KayaliO., M.N. Haque, B. Zhu ${ }^{[8]}$ studied the effect of polypropylene and steel fibers on high strength light weight concrete. The flyash was used to replace fines and the use of polypropylene at $0.56 \%$ by volume causing increase in indirect tensile strength by $90 \%$ and increase in indirect rupture by $20 \%$. 
9. Neelesh Kumar Singh, Rohit Kumar Shakya, Prerit Saxena, Rishabh Sharma ${ }^{[9]}$,the study emphasized on the replacement of cement by fly ash in 5\%,10\%, 15\%, 20\% ratios. Without using any admixtures, their experiment concluded that $10 \%$ fly ash content gives more strength than other ratios. Increase in fly ash content results in lesser strength and more water requirement.

10. P. Nath and P. Sarker ${ }^{[10]}$ the research work included replacement of cement with fly ash by $30-40 \%$, which resulted in compressive strength of $60 \mathrm{MPa}$ after 28 days and $85 \mathrm{MPa}$ after 56 days of curing. The strength for $30 \%$ replacement was more than that of $40 \%$ replacement. The researchers also tested the chloride ion permeability and found out that it reduced by $35-45 \%$ and more after 28 days. Fly ash reduced the drying shrinkage as well as the sorptivity of the concrete.

11. Snehal Afiniwala, Nirav Patel, Dr. Indrajit Patel ${ }^{[11]}$, theystudied the outcome of fly ash on Self compacting concrete (SCC). M20 and M25 mixtures were made by 50\%, 55\% and 60\% replacement of cement by class F fly ash. Tests were conducted to determine the rheological properties of concrete. It was found out that all the properties satisfied the standards for 50\% and 55\% of replacement. Further increase in fly ash caused reduction in flow of concrete. Therefore, it can be said that SCC of low cost can be developed by using fly ash.

12. Indrajit Patel and C D Modhera ${ }^{[12]}$ based their experimental work on the effect of polyester fibers in high volume fly ash concrete (HVFA). Trail mix for M25, M30, M35, M40 HVFA concrete were casted with 50,55 and $60 \%$ replacement by fly ash. The compressive strength for $0.25 \%$ of fiber was tested. It was observed that the 28-day compressive strength for M25 50\% fly ash mix increased by $13 \%$ after adding fiber to HVFA concrete. For M30, the strength increased by 20\%. For M35 and M40, strength increased by $15 \%$. As the fly ash content was increased from $50 \%$ to $60 \%$, there was reduction in strength by $3-5 \%$ for all the trail mixes. The strength and slump values for all the mix were within the desired standard limits. The optimum compressive and flexural strength was obtained at 55\% replacement of fly ash for plain as well as polyester fiber concrete.

13. P. Vipul Naidu and Pawan Kumar Pandey ${ }^{[13]}$ the study was conducted to reach the target strength for M40 grade by replacing cement up to 75\% with fly ash and lime to reduce the cost of production. Two trail mix were made, one without lime and another with lime, using superplasticizer in both the trails. The trail mix without lime showed that 28-day comparable strength up to $45 \mathrm{MPa}$ can be obtained for $65 \%$ fly ash with $46 \%$ reduction in cost, further increase in fly ash caused huge reduction in strength. Second trail mix with $10 \%$ lime showed that 28 -day compressive strength up to $39 \mathrm{MPa}$ can be developed for $75 \%$ cement replacement with $41 \%$ reduction in cost.

\section{Conclusion}

1. Use of flyash reduces the voids and cracks formation and corrosion.

2. Flyash increases workability, durability and minimizes the water demand.

3. Flyash reduces the overall cost by $10-30 \%$ of that of concrete when $50 \%$ of cement is replaced and $46 \%$ cost reduction when $65 \%$ cement is replaced.

4. The setting time is generally increased by approx. 2 hours by adding flyash to it.

5. The development of compressive strength, flexural strength is slow however it holds pace in later days from 7 to 28 days and from 28 to 56 days, 91,182 and 365 days.

6. With increase in content of fly ash, air content increases whereas unit weight decreases.

7. With increase in content of flyash, air content increases and unit weight decreases.

8. Flyash content increases workability and drainage characteristics.

9. There is a limitation in addition of flyash content in concrete so that workability is maintained.

10. Up to 55\% cement can be easily replaced by fly ash if used along with polyester fibers.

11. Self-Compacting Concrete can also be developed for $55 \%$ replacement of cement by fly ash.

12. With increase in fly ash content, sorptivity and shrinkage of concrete also decreases.

13. For HVFA concrete, admixtures help to obtain higher strength for negligible change on cost.

\section{References}

[1]. P. Kumar Mehta, High-performance, high-volume fly ash concrete for sustainable Development, International Workshop on Sustainable Development and Concrete Technology, Beijing, May 20-21, 2004.

[2]. Chung-Ho Huang, Shu-Ken-Lin, Chao-Shun Chang, How-ji-Chen, Mix proportions and mechanical properties of concrete containing very high-volume of Class F fly ash, ELSEVIER.

[3]. L.K Crouch, Ryan Hewitt, Ben Byard, High Volume Fly Ash Concrete, 2007 World of Coal Ash (WOCA), May 7-10, 2007, Northern Kentucky, USA. 
[4]. Yash Shrivastava and Ketan Bajaj, Performance of Fly Ash and High Volume Fly Ash Concrete in Pavement Design, International Proceedings of Computer Science and Information Technology,Singapore, Vol. 28 (2012).

[5]. Muhammad shahzada, Tufail, Khan, Bora Genturk and Jianqiang Wei, Effect of Elevated Temperature on Mechanical Properties of Limestone, Quartzite and Granite Concrete, International Journal of Concrete Structures and Materials Vol.11, No.1.

[6]. P.S. Song and H.W. Hwang, Mechanical properties of High Strength steel reinforced concrete, Construction and Building Materials 18 (2004) 669-673.

[7]. Bing Chen, Juanyu Liu, (2005), Properties of Light Weight Expanded Polystyrene concrete reinforced withsteel fibers, Cement and concrete research, Vol. 34 (2004) 1259-1263.

[8]. Kayali O., M.N. Haque, B. Zhu, Some characteristics of high strength fiber reinforced lightweight aggregate concrete, ELSEVIER, Vol. 25, Issue 2, 2003.

[9]. Neelesh Kumar Singh, Prerit Saxena, Rishabh Sharma, Rohit Kumar Shakya, A Comparative Study on Partial Replacement of Cement with Fly ash \& Granite Powder, IOSR Journal of Mechanical and Civil Engineering, volume 13.

[10]. P. Nath, P. Sarker, Effect of Fly Ash on the Durability Properties of High Strength Concrete, ELSEVIER volume 14, 2011.

[11]. Snehal Afiniwala, Dr. Indrajit Patel, Nirav Patel, Effect of High Volume Fly ash on Rheological Properties of Self Compacting Concrete, International Journal of Emerging Technology and Advanced Engineering, Vol. 3, Issue 7, 2013.

[12]. Indrajit Patel, C D Modhera, Study effect of polyester fibers on engineering properties of high volume fly ash concrete, Journal of Engineering Research and Studies, Vol. 2, Issue 1, 2011.

[13]. P. Vipul Naidu and Pawan Kumar Pandey, Replacement of Cement in Concrete, International Journal of Environmental Research and Development, ISSN 2249-3131 Volume 4, Number 1 (2014). 